\title{
MÉXICO: DE LA EDUCACIÓN INDÍGENA A LA EDUCACIÓN RURAL
}

\author{
Mexico: From indigenous education to rural education
}

\author{
Marco A. Calderón Mólgora* \\ Fecha de recepción: 29/03/2017 • Fecha de aceptación: 04/09/2017
}

Resumen. Este ensayo refiere a la historia de la educación rural en México en el contexto de la configuración del Estado que surge a consecuencia de la revolución social de la década de 1910. Muestra la forma en que la percepción del llamado "problema indígena» se transforma en «el problema rural», y la manera en que dicha transformación se vincula a las estrategias del gobierno federal para dar solución a uno de los grandes "problemas nacionales». Ante el hecho de que los proyectos de educación rural dieron paso a dificultades y resistencias, la Secretaria de Educación Pública (SEP) ensayó distintos métodos con el propósito de encontrar estrategias adecuadas para «civilizar»y «forjar patria». El trabajo hace énfasis en algunas de esas estrategias para educar a la población que habitaba en el campo en la década de 1920. A pesar de que los políticos e intelectuales hicieron énfasis en la urgencia de rescatar las necesidades locales en el proceso de construcción de la nación moderna, un elemento central de este proceso es que la educación rural buscaba la industralización de la producción agrícola, lo que implicaba cambios muy significativos en la vida cotidiana de las comunidades indígenas y campesinas.

Palabras clave: Educación pública; Estado; Problema indígena; Problema rural.

Abstract. This essay refers to the history of rural education in Mexico in the context of the state configuration that emerges as a result of the social revolution during the decade of 1910. It shows how the perception of the "the indigenous problem» is transformed into "the rural problem» and the way in which such transformation is related to the strategies of the federal government to solve one of the most important "national problems». Since the rural education project faced difficulties and resistances, the Ministry of Public Educa-

\footnotetext{
"Centro de Estudios Antropológicos. El Colegio de Michoacán. Martínez de Navarrete 505. Fraccionamiento Las Fuentes. Zamora, Michoacán, 59699 México. calderon@colmich.edu.mx
}

Cómo citar este artículo: Calderón Mólgora, Marco A. «México: de la educación indígena a la educación rural». Historia y Memoria de la Educación 7 (2018): 153-190. 
tion tested different methods in order to find strategies to «civilize» and "forging a sense of the fatherland». This work emphasizes some of the strategies undertaken by the Ministry of Public Education to educate the population that lived in the countryside in the 1920s. Although politicians and intellectuals emphasized the urgency of rescuing local needs in the process of building the modern nation, a central element of this process is that rural education sought the industrialization of agricultural production, which implied very significant changes in the everyday life of indigenous and peasant communities.

Keywords: Public education; State; Indigenous problem; Rural problem.

\section{INTRODUCCIÓN}

A lo largo del tiempo, bajo diferentes matices, se reproducen una serie de ideas y prejuicios en torno al llamado "problema indígena» y a la manera de resolverlo. ${ }^{1}$ Si bien entre dichas percepciones y la realidad cotidiana existía una distancia significativa, ${ }^{2}$ tales representaciones son relevantes dado que constituyen las bases ideológicas sobre las que se elaboraron planes y programas para alfabetizar y educar a la población que habitaba en el campo. Muchos eran los «defectos» que las élites decimonónicas atribuían al indígena, a quien se le concebía como un ser melancólico, desconfiado, tímido, hipócrita, egoísta, falto de iniciativa, apático, con poca imaginación, mentiroso e incluso indolente. No sabía reír y no sabía disfrutar de la vida. Era además reacio a socializar con gente de otros pueblos o grupos étnicos; era también concebido como un ser fanático y supersticioso, proclive a involucrarse en las fiestas religiosas y a emborracharse con frecuencia. Si bien cultivaba el campo, se consideraba que no tenía aspiraciones; no buscaba cambiar su situación y no les interesaba incrementar la producción para insertarse al mercado. ${ }^{3}$

Quizás como consecuencia de la revolución mexicana, en la década de 1920 inicia una nueva etapa de la historia en relación con el «proble-

\footnotetext{
${ }^{1}$ Martin Stabb, «Indigenism and Racism in Mexican Thought: 1857-1911», Journal of Inter-American Studies, I (4), (1959): 405-423; Beatriz Urías, Indígena y Criminal: Interpretaciones del derecho y la antropología en México (México: Universidad Iberoamericana, 2000).

${ }^{2}$ Guy Rozat, Los orígenes de la Nación. Pasado indígena e historia nacional (México: Universidad Iberoamericana, 2001), 12.

${ }^{3}$ Luis González y González, «El subsuelo indígena», Historia moderna de México, La República Restaurada, La vida Social (México-Buenos Aires: Editorial Hermes, 1974).
} 
ma indígena» y la forma de darle solución. Con la constitución de la Secretaría de Educación Pública (SEP) en 1921 se intensifica la injerencia del gobierno federal en las comunidades rurales a través de los maestros y las escuelas; con todo, durante la administración presidencial de Plutarco Elías Calles (1924-1928), el «problema indígena» se convierte en un "problema rural». La convicción de que tanto las comunidades indígenas, como las localidades rurales mestizas, presentaban básicamente las mismas problemáticas sociales - a «excepción» del desconocimiento del idioma español—, introduce un matiz significativo en cuanto a la concepción del "problema indígena». Se hizo mayor énfasis en las diferencias sociales y culturales entre lo rural y lo urbano. El atraso de las comunidades rurales, llego a representar, para el gobierno federal, «el problema de la vida rural», el cual debía ser resuelto para que el país figurara «entre los pueblos civilizados». ${ }^{4}$ Un elemento central de esta historia es que la educación rural buscaba la industrialización del campo, lo que implicaba cambios drásticos en la organización social, en los hábitos de trabajo, en las expectativas, en las formas de pensar, en las creencias vernáculas, en suma, en el «ethos moral» de la población que habitaba en el campo. ${ }^{5}$ Persistían algunos elementos de la antigua convicción liberal decimonónica en cuanto a la supuesta «degeneración» del indígena; lo que parece haber cambiado es la explicación en cuanto a las causas del «atraso social»y las formas de resolverlo. ${ }^{6}$

\section{PRIMEROS PASOS}

El 30 de mayo de 1911 el Congreso Federal aprobó un decreto sobre Instrucción Rudimentaria en la República. El artículo 1. ${ }^{\circ}$ autorizaba al poder Ejecutivo el establecimiento de escuelas con el propósito de enseñar «a los individuos de la raza indígena a hablar, leer y escribir el castellano», así como instruirlos en la ejecución de «las operaciones funda-

\footnotetext{
${ }_{4}$ «Platica del Dr. J. M. Puig Casauranc, Secretario de Educación Pública, a los miembros de las Misiones Culturales, 25 de febrero de 1927 », Boletín de la Secretaría de Educación Pública, XVII (5), (1927).

${ }^{5}$ Philip Corrigan y Derek Sayer, «El gran Arco, La formación del Estado Inglés como revolución cultural», en Antropología del Estado, Dominación y prácticas contestatarias en América Latina, eds. María y Pamela Calla Lagos (Bolivia: PNUD, 2007), 41-116.

${ }^{6}$ Mary Kay Vaughan, State, Education and Social Class in Mexico, 1880-1928, (Chicago: Universidad de Illinois, 1982); Engracia Loyo, Gobiernos revolucionarios y educación popular en México, 19111928 (México: El Colegio de México, 1999); Elisa Ramírez Castañeda, La educación indígena en México (México: UNAM, 2006).
} 
mentes y más usuales de la aritmética». Otros artículos establecían que la educación básica sería de dos años y que el número de escuelas crecería en la medida en que los recursos del Ejecutivo lo permitieran. Sin importar sexo y edad, todas las personas analfabetas que tuvieran la voluntad de instruirse de manera voluntaria habrían de tener la oportunidad de asistir a dichos establecimientos. Para estimular la asistencia a la escuela, el ejecutivo distribuirá «alientos y vestidos a los educandos», tomando en cuenta las necesidades y las circunstancias locales y regionales. Esa disposición legal no contravenía las leyes vigentes sobre instrucción obligatoria en los Estados, en los territorios y el Distrito Federal. ${ }^{7}$

La Secretaría de Instrucción Pública y Bellas Artes envió a los estados y los territorios «Instaladores de Escuelas Rudimentarias»; además, creó una sección para la organización de los asuntos vinculados con los instaladores y las nuevas escuelas. Ese personal tenía como obligación «explorar las regiones más incultas del país» y proponer la constitución de escuelas rudimentarias en puntos estratégicos considerando la «división natural étnica o delimitada por el uso de un idioma o dialecto regional»; los instaladores habría de elaborar un presupuesto para la creación de las escuelas y para su sostenimiento; debían además encontrar a personas que reunieran «condiciones de aptitud y moralidad» con el objetivo de dirigir los establecimientos. ${ }^{8}$

A su juicio de Alberto J. Pani, Subsecretario de Educación Pública, el establecimiento de Escuelas Rudimentarias, constituía el mayor reto que enfrentaba el país en materia de educación popular. El problema era de grandes dimisiones y poseía varias aristas, como «el nivel mental y la naturaleza de la población», además del bajo presupuesto. En 1910 existía una población total de 15,139,885 habitantes, de los cuales 10,324,484 no sabían escribir ni leer. Otro problema significativo era «la falta de homogeneidad étnica de la población». Si bien el propio Pani reconoce la dificultad de establecer una clasificación precisa, a su juicio era factible dividir a la población en tres grupos «étnicos fundamentales» tomando en cuenta sus «rasgos exteriores» más sobresalientes: uno conformado blancos y criollos; el segundo el de los mestizos, esto es, la población que

${ }^{7}$ Francisco J. Pani, La instrucción rudimentaria en la República (México: Secretaría de Instrucción Pública, 1912), 11.

${ }^{8}$ Pani, La instrucción rudimentaria en la República, 12. 
resultó del «cruzamiento» de diversas razas; el tercero se componía de «indios puros» (poco más de tres millones). ${ }^{9}$

Frente al complejo panorama derivado de la enorme heterogeneidad cultural y diversidad regional, educar a la población «inculta» representaba un problema de grandes dimensiones. El decreto establecía que a las escuelas rudimentarias podrían concurrir por voluntad propia todos los que tuvieran interés en alfabetizarse. Considerando que diez millones de personas no sabían leer, escribir y desconocían las operaciones elementales de la aritmética, los 300 mil pesos designados resultaban totalmente insuficientes. Según los cálculos de Pani, entre los años de 1909 y 1910, existían en todo el país 14,418 escuelas oficiales y particulares, atendiendo a una población de 900 mil alumnos. Considerando que la población escolar era de 3,6 millones, existía entonces un total de 2,7 millones de infantes que no tenían acceso a la educación formal. Para atender a toda esa población se requieran 67.500 escuelas rudimentarias en todo el país, lo cual implicaba un presupuesto mínimo de 40,5 millones de pesos anuales. ${ }^{10}$ Pese a todo, fue poco lo que se hizo a ese respecto en la década de 1910 , en parte como consecuencia de la violencia revolucionaria y en parte por los estragos de la influencia española. Más de un millón de personas perdieron la vida en esa década. Según Moisés Sáenz, en 1920 el 63,29\% de la población no sabía leer ni escribir. ${ }^{11}$ El censo de 1921 registró un total de 14,5 millones de habitantes, de los cuales 1.820.844 fueron clasificados como indígenas [12,55\%]; la población mayor a 10 años que declaró ser analfabeta era de 6.879 .348 , lo que representaba el $47.44 \%$ del total. ${ }^{12}$

\section{LA VISIÓN DE JOSÉ VASCONCELOS}

Si bien en diferentes estados de la República se realizaron esfuerzos significativos en cuanto a la educación indígena y rural, sobre todo durante el último tercio del porfiriato, sería en la segunda década del siglo xx cuando el gobierno federal tendría la capacidad de multiplicar escuelas e

\footnotetext{
${ }^{9}$ Pani, La instrucción rudimentaria en la República, 14.

${ }^{10}$ Pani, La instrucción rudimentaria en la República, 17-18.

11 «The Norman Wait Harris Memorial Fundation, Third Institute, Educacional Policy of the Mexican Government», Caja III, Colección Especial, Biblioteca Regestein, Universidad de Chicago.

${ }^{12}$ Resumen del Censo General de Habitantes, Departamento de la Estadística Nacional, 30 de noviembre de 1921.
} 
incrementar el número de maestros en todo el territorio nacional. José Vasconcelos fue nombrado rector de la Universidad Nacional el 4 de junio de 1920, quien convocó a todos los mexicanos a participar en una campaña de alfabetización. ${ }^{13}$ A su juicio, una cuestión básica era enseñar a leer y escribir el español a la gran masa de «gente ignorante» que conformaba entonces la mayor parte de la población mexicana. Para luchar en contra del analfabetismo se constituyó «un cuerpo de Profesores Honorarios de Educación Elemental». Echando mano de textos y útiles a su disposición, esos maestros habrían de enseñar a leer y escribir en poco tiempo. ${ }^{14}$ Después de cuatro meses de trabajo estaban inscritos poco más de 1,500 profesores en todo el país. Pese a todo, muchos mexicanos permanecían en la ignorancia, lo cual representaba un "peligro inmenso» $y$ una amenaza constante para la patria. ${ }^{15}$

Vasconcelos elaboró un proyecto para la creación de un organismo federal encargado de la educación pública en México, siendo creada la Secretaría de Educación Pública (SEP) en el año de 1921. La centralización de la educación era un aspecto fundamental en el proceso civilizador de un país tan heterogéneo culturalmente como México. ${ }^{16} \mathrm{La}$ propuesta establecía un ministerio para toda la República conformado por tres departamentos: Escuelas, Bibliotecas y Bellas Artes. ${ }^{17}$ En todo el país habrían de fundarse escuelas rurales, instituciones en las que se enseñarían «trabajos manuales, cultivos, algo de ciencia aplicada y consejos prácticos sobre uso de máquinas y métodos modernos para mejorar las industrias locales». La nueva secretaría enviaría «maestros ambulantes» para recorrer pueblos y «rancherías predicando la buena nueva de la regeneración por el trabajo, por la pericia y por la virtud». Vasconcelos enfatiza de manera tajante su oposición a la posibilidad de tratar al indígena como un ser especial y distinto «del resto de la población». De hecho, la campaña de educación indígena fue organizada «a la española, con incorporación del indio» a México. ${ }^{18}$ Sin embargo, una cosa era lo

\footnotetext{
13 José Vasconcelos, El Movimiento Educativo en México (México: Talleres Gráficos de la Nación, 1922), 5.

${ }^{14}$ Vasconcelos, El Movimiento Educativo en México, 14-15.

15 Vasconcelos, El Movimiento Educativo en México, 88-89.

16 José Vasconcelos, Memorias II. El desastre (México, FCE, 1982), 13.

${ }^{17}$ Vasconcelos, Memorias II. El desastre, 19.

${ }^{18}$ Vasconcelos, Memorias II. El desastre, 20.
} 
que Vasconcelos expresa en sus memorias y otra lo que algunos de sus colaboradores pusieron en práctica. Además, la legislación vinculada a la creación de la SEP, en su artículo sexto, relativo al Departamento Escolar, propuso «la creación de escuelas especiales para la educación de los indios», las cuales habrían de establecerse en "regiones densamente pobladas por indígenas». En ellas se enseñaría «la lengua castellana», así como otros «rudimentos para asimilaros» a la civilización. Una vez aprendido el español, los indígenas pasarían «a las escuelas rurales primarias». ${ }^{19}$

\section{MAESTROS MISIONEROS}

En el año de 1922 se propuso la creación del Departamento de Educación y Cultura Indígena (DECI). Su principal impulsor, el diputado del Partido Liberal Constitucionalista, Juan B. Salazar, argumentó sobre la necesidad de su creación para emprender la «regeneración» de los indígenas, que, según sus cálculos, sumaban cinco y medio millones en toda la República. No sólo había que alfabetizar al indio; era imprescindible «enseñarle a vivir» y arrancar de su mente la idea de ser una «eterna bestia de carga». ${ }^{20}$ Vasconcelos aceptó esa innovación «sin gran entusiasmo» y en marzo de 1922 señaló que ese departamento "tenía una existencia provisional», el cual habría de desaparecer en el momento en que los indígenas tuvieran la capacidad de asistir a las escuelas rurales. ${ }^{21}$

El primer jefe del DECI sería Lauro G. Caloca, militar y revolucionario nacido en Zacatecas en el año de 1883. La dependencia bajo su cargo contaba con recursos suficientes para contratar cien maestros misioneros y cien residentes. Para mayo de 1922 existían en la práctica «setenta y siete» de los primeros y «trece de los segundos». La visita a muy distintas localidades y zonas indígenas en diferentes puntos de la República fue una de las primeras tareas de los maestros misioneros. Entre sus múltiples responsabilidades, debían rendir informes en relación con «las condiciones escolares de cada centro». Casi todos los maestros misioneros

\footnotetext{
${ }^{19}$ Vasconcelos, El Movimiento Educativo en México, 70.

${ }^{20}$ Claude Fell, «La creación del Departamento de Cultura Indígena a raíz de la Revolución Mexicana», Educación rural e indígena en Iberoamérica, coord. Pilar Gonzalbo (México, El Colegio de México, 1999), 115.

${ }^{21}$ Fell, «La creación del Departamento de Cultura Indígena a raíz de la Revolución Mexicana», 116.
} 
se concentraron en estados con mayor población indígena como Oaxaca, Puebla, Chiapas, Veracruz, San Luis Potosí, Nayarit, Morelos y Michoacán, faltando aun asignar plazas para Sonora y Yucatán, estados cuya población indígena requería también de «atención especial». ${ }^{22}$

Aquellos primeros misioneros no sólo localizaron núcleos indígenas, sino que analizaron las condiciones económicas de los pueblos, así como la "clase de cultura» que debían impartir; seleccionaron a las personas que habrían de desempeñarse como maestros. Otra responsabilidad fue estudiar y analizar las industrias locales con el propósito de mejorarlas y desarrollarlas. Además, tenían que elaborar proyectos y organizar exposiciones permanentes de los productos elaborados; debían buscar también la cooperación de ingenieros agrónomos de la Secretaría de Agricultura y Fomento con el objetivo de analizar la calidad de la tierra, los "sistemas de labranza», las clases de cultivos, las temporadas de lluvia, las condiciones climatológicas, las vías de comunicación, los mercados de consumo y los salarios. Con el objetivo de facilitar su labor, un punto fundamental era que tanto los maestros misioneros como los maestros residentes, es decir, los profesores que los primeros entrenaban, habrían de conocer "el dialecto del grupo indígena» así como las características de la región en la que desempeñaban sus labores. ${ }^{23}$

Tomando en cuenta «los estudios y las observaciones» realizadas por los maestros misioneros, Caloca llegó a la conclusión de que la educación urbana no constituía en realidad un problema. En las ciudades era suficiente invertir dinero en la contratación de maestros y en la edificación de escuelas para lograr civilizar a la gente ignorante. En contraste, los habitantes de las zonas rurales representaban un verdadero problema. ${ }^{24}$ De un total de diez y seis millones de habitantes, sólo cuatro millones vivían «bajos los auspicios de la civilización»; los doce restantes eran analfabetos, población que permanecía desvinculada «de los intereses materiales y culturales de la República». Muchos de ellos desconocían el español y carecían «de los conocimientos más elementales»; sus cabezas

\footnotetext{
${ }^{22}$ Lauro Caloca, «Departamento de Cultura Indígena. Informe del Jefe del Departamento», Boletín de la Secretaría de Educación Pública, I (1), (1922): 573.

${ }^{23}$ Caloca, «Departamento de Cultura Indígena. Informe del Jefe del Departamento», 574.

${ }^{24}$ Lauro Caloca, «Exposición de motivos de las bases del Congreso de Misioneros que se celebrará en la capital de la República», Ethnos, Revista dedicada al estudio y mejora de la población indígena de México, 2. ${ }^{a}$ época, I (1), (1922-1923): 63-72.
} 
estaban llenas de «vicios ancestrales» derivados de la violenta conquista española. Caloca se pregunta cómo sería posible descender, de manera paulatina, «al fondo de la conciencia de esos habitantes». El problema era muy difícil de resolver. No era suficiente destinar recursos monetarios; urgía contar «con hombres de acción» no sólo dispuestos a ir al campo sino con la capacidad de llegar a la conciencia de las personas y enseñarles a vivir. Los ignorantes, los analfabetos, requerían de la ayuda de las personas conscientes. ${ }^{25}$

Por otro lado, como indica Caloca, muchos habitantes del campo migraban a las ciudades, en busca de oportunidades laborales; sin embargo, al llegar, a los centros de población urbana se enfrentaban a diversos problemas. Entre otras cosas, los migrantes carecían del entrenamiento adecuado para ingresar al mercado laboral. El Departamento de Asuntos Indígenas se propuso revertir dicha tendencia. Ya que la tierra para el cultivo constituía «la base fundamental de todas las prosperidades» y ofrecía al hombre la libertad como el «bienestar económico y social», no solo había que frenar la migración del campo a la ciudad, sino que había incluso que fomentar la migración de la ciudad al campo. Por lo tanto proponía «organizar una falange de maestros misioneros» que tuvieran la capacidad de crear conciencia e inculcar la fe en el progreso entre los habitantes del campo. ${ }^{26}$

El maestro rural debía dominar el «dialecto», además de conocer algo de ciencia. Voluntad y empeño constituían otros dos elementos fundamentales del profesor ideal. Con el propósito de alcanzar las metas que la SEP promovía, los habitantes indígenas debían adquirir en un corto período varias habilidades: lectura y escritura en castellano, un conocimiento de las operaciones básicas de la aritmética; también debían cobrar conciencia sobre el hecho de que el cultivo de la tierra era la base de la prosperidad de cualquier país. ${ }^{27}$ Esos conocimientos y habilidades podían ser alcanzados a través de una educación concreta, que permitiera levantar «los primeros muros de ese edificio que se llama nacionalidad».

\footnotetext{
${ }^{25}$ Caloca, «Exposición de motivos de las bases del Congreso de Misioneros que se celebrará en la capital de la República», 64.

${ }^{26}$ Caloca, «Exposición de motivos de las bases del Congreso de Misioneros que se celebrará en la capital de la República», 65.

${ }^{27}$ Caloca, «Exposición de motivos de las bases del Congreso de Misioneros que se celebrará en la capital de la República», 65.
} 
Tanto los maestros misioneros, como los profesores residentes, debían de contribuir a la recolección de la información necesaria para calcular el número y las características de «los núcleos indígenas más numerosos de la República». ${ }^{28}$

Otro punto crucial sobre «la educación de las razas indígenas de la República» refiere a la diversidad de «dialectos». El idioma, según Caloca, constituía el medio de expresión de «las manifestaciones internas del individuo», al operar «directamente en su propia vida». La confianza y la fraternidad encontraban su base en un idioma común. Para imponer el español como un idioma oficial, los maestros misioneros debían hablar «el dialecto» de la «raza indígena» con la que habrían de trabajar. Al no existir un número suficiente de maestros que cumpliera dicho requisito, una estrategia era reclutar a indígenas, que habiendo tenido la necesidad de salir de sus lugares de origen para trabajar, hubiesen aprendido el español. A ellos sería posible entrenarlos para que regresaran como maestros a sus lugares sus pueblos o rancherías. ${ }^{29}$

Durante un Congreso de Maestros Misioneros celebrado en septiembre de 1922 se solicitó elevar el número de profesores ambulantes a 300 y de maestros residentes a 20,000. Otra conclusión fundamental se refiere a la necesidad de considerar la educación como un "problema social», así como «la dotación de tierras cultivables para las escuelas». El lema del congreso fue «la tierra como fuente suprema de bienestar económico y social». ${ }^{30}$ Poco tiempo después, Roberto Medellín, jefe del Departamento Escolar, organizó cursos de invierno cuyo objetivo era lograr «el mejoramiento cultural, profesional y práctico de los maestros federales», estando dirigido de manera especial a los maestros rurales. El objetivo central de la escuela y la educación era «conseguir, para la vida rural, un ambiente de mayor comodidad y de mayor progreso». Durante los cursos se impartieron clases de arboricultura, hortalizas, trabajos en el campo, técnica de la enseñanza, psicología de la educación, organización de la escuela rural, coros escolares, juegos, deportes, puericultura, economía

\footnotetext{
${ }^{28}$ Caloca, «Exposición de motivos de las bases del Congreso de Misioneros que se celebrará en la capital de la República», 66.

${ }^{29}$ Caloca, «Exposición de motivos de las bases del Congreso de Misioneros que se celebrará en la capital de la República», 67.

${ }^{30}$ Secretaría de Educación Pública, Las Misiones Culturales 1932-1933 (México: Secretaría de Educación Pública, 1933), 7.
} 
doméstica, agricultura, industrias agrícolas como lechería y conservación de frutas. ${ }^{31}$

Los misioneros serían los encargados de establecer, organizar y difundir la labor educativa de la SEP. En teoría eran libres para «introducir y llevar a cabo todas aquellas reformas» que buscaran el «mejoramiento de las instituciones» del departamento; sin embargo, la unificación «del personal docente en cuanto a los principios científicos y educativos» constituía un aspecto crucial. Los maestros misioneros debían vigilar el funcionamiento de las escuelas rurales. Otra atribución importante era la posibilidad de proponer al departamento la contratación de personal docente que fuese necesario para completar «la planta de empleados de una zona, así como las sanciones» que habrían de aplicarse a los maestros que no cumplieran de forma adecuada con sus responsabilidades. Debían formular recomendaciones «verbales y escritas», además de proponer trabajos prácticos para superar las deficiencias. Otra de sus tareas era difundir información sobre «fiestas, exposiciones, excursiones y de trabajos especiales», así como dar cuenta a la SEP de las autoridades locales que buscaran entorpecer el trabajo de los maestros. Una facultad adicional era conceder licencias económicas hasta por tres días, tres veces al año, a los maestros que así lo solicitaran, además de desempeñar comisiones que la SEP les encargara de manera especial. Debían también solicitar constancias a las autoridades municipales en cuanto a las fechas de ingreso y salida de las comunidades de sus lugares de trabajo. ${ }^{32}$

Los misioneros tenían responsabilidades en relación con la investigación social. De hecho estaban obligados a elaborar informes sobre las localidades y las regiones en las que trabajaban en cuanto al número de habitantes, la composición étnica de la población, los «idiomas predominantes», además de recolectar datos en torno a orografía, hidrografía, recursos naturales, condiciones climatológicas, productos animales y vegetales, industrias locales, vías de comunicación, porcentajes de alfabetismo, número de escuelas en funcionamiento, costumbres (inclui-

\footnotetext{
${ }^{31}$ Secretaría de Educación Pública, Las Misiones Culturales 1932-1933, 8.

${ }^{32}$ Enrique Corona, «Informe que rinde el Jefe del Departamento de Educación y Cultura Indígena al Ciudadano Secretario de Educación Pública», Boletín de la Secretaría de Educación Pública, I (4), (1923): 401-402.
} 
dos «vicios» y «virtudes»), así como la disposición o resistencia de la población a la educación federal y los métodos de trabajo locales, sin importar si eran "primitivos, atrasados o modernos». Los informes eran mensuales e incluían datos sobre el número de escuelas fundadas en el período, escuelas visitadas, labores desarrolladas en ellas, además de las instituciones educativas clausuradas. ${ }^{33}$

A finales del primer semestre del año de 1923 existían un total 112 profesores ambulantes, 100 de los cuales prestaban en distintos estados mientras que otros diez desempeñaban «trabajos culturales» en varias entidades federativas al estar adscritos a las Misiones Culturales. En relación con los maestros residentes, se otorgaron 876 nombramientos, 715 de los cuales estaban en servicio activo adscritos a distintas dependencias: 578 al Departamento de Cultura Indígena, 126 a la Campaña de alfabetización, cinco al Departamento de Bellas Artes y seis al Departamento Escolar. ${ }^{34}$ Según las estadísticas de la SEP, del año de 1922 a 1923 el número de escuelas rurales pasó de 309 a 569; mientras tanto, el número de maestros residentes se incrementó 84,39\%, pasando de 314 a 579. El crecimiento del número de alumnos en el mismo periodo fue muy importante: de 17,925 aumentó a 34,819 lo que significó un incremento de $94,24 \%$. A finales del año, 904 maestros rurales residentes estaban atendiendo a 49.640 estudiantes mientras que el número de maestros ambulantes permaneció siendo el mismo. ${ }^{35}$

La SEP emitió varias circulares en relación con los profesores ambulantes. La número quince señala la responsabilidad de enseñar a «los indios los rudimentos» de "civilización»; tenían que buscar "penetrar la mentalidad» de los educandos con la finalidad de influir sobre ellos; debían «descubrir la porción de verdad» que existía en algunos de los «usos y conocimientos» indígenas. En otras palabras, el misionero habría de estar abierto e investigar todo el «extraño acervo de conocimientos útiles o curiosos» de los indios «tales como el uso medicinal de

\footnotetext{
${ }^{33}$ Corona, «Informe que rinde el Jefe del Departamento de Educación y Cultura Indígena al Ciudadano Secretario de Educación Pública», 403.

${ }^{34}$ Corona, «Informe que rinde el Jefe del Departamento de Educación y Cultura Indígena al Ciudadano Secretario de Educación Pública», 391.

${ }^{35}$ Enrique Corona, «Informe que rinde el Jefe del Departamento de Cultura Indígena al ciudadano Secretario de Educación Pública, relativo a las labores desarrolladas en el segundo semestre de 1923 y primer trimestre de 1924», Boletín de la Secretaría de Educación Pública, II (5-6), (1924): 588.
} 
plantas, observaciones meteorológicas, creencias y prácticas de vida». Dichos saberes, incluso «las supersticiones debidamente recolectadas y fielmente transcritas», resultaban útiles "para completar el estudio de la mente humana», tanto «en sus aberraciones» como «en sus aciertos». Otra de sus responsabilidades era «dar a conocer al mundo el alma de los indígenas»; al mismo tiempo, el misionero tenía que poner al indio «en comunicación con la ciencia acumulada por el resto de la humanidad durante el curso de los siglos». Los maestros habrían de enviar al departamento los datos que consideraran «originales sobre usos y costumbres», sobre todo en relación con el uso medicinal de las plantas, además de los «procedimientos industriales, primitivos o avanzados, prácticas religiosas o simplemente supersticiones; particularidades de trajes, juegos, músicas y bailes de las distintas regiones». Otro aspecto crucial era no asumir actitudes arrogantes al investigar las «deficiencias de la cultura» local. ${ }^{36}$

Después de varios meses de trabajo, la SEP consideró que las actividades de los Maestros Misioneros constituían una «mera exploración»; en cuanto a la investigación social, las autoridades planteaban que su desempeño resultaba muy poco satisfactorio. Bajo tales circunstancias habría que proceder de otra forma. Era necesario «emprender una verdadera campaña» que hiciera "efectiva la obra de civilización de los indios». La mayoría de los misioneros eran normalistas que carecían de conocimientos indispensables sobre pequeñas industrias, producción agrícola, cuidado y crianza de animales domésticos; además, muchos de ellos no estaban llevando a cabo las acciones de tipo social que en teoría debían «desarrollar para atraer a los indios y lograr su redención». Peor aún, muchos habían logrado su nombramiento como maestros por «influencias políticas» y algunos se dedicaban a actividades distintas a la enseñanza; incluso hubo quienes se entregaron "al vicio», lo que desacreditaba a la secretaría y generaba desconfianza entre la población. ${ }^{37}$ En otras palabras, aquellos profesores ambulantes eran muy diferentes a los que la SEP consideraba ideales.

\footnotetext{
${ }^{36}$ Corona, «Informe que rinde el Jefe del Departamento de Educación y Cultura Indígena al Ciudadano Secretario de Educación Pública», 407-408.

${ }^{37}$ Corona, «Informe que rinde el Jefe del Departamento de Cultura Indígena al ciudadano Secretario de Educación Pública, relativo a las labores desarrolladas en el segundo semestre de 1923 y primer trimestre de 1924», 600 .
} 


\section{LA CASA DEL PUEBLO}

Según Enrique Corona, segundo director del DECI, los indígenas vivían en una "angustiosa y triste situación», al padecer múltiples carencias; muchos de ellos no sabían español, «habitaban en regiones apartadas y mal comunicadas con el resto del país» y sus condiciones económicas eran difíciles. Por si fuera poco «el tratamiento injusto» recibido por largo tiempo había generado en ellos «un estado abúlico» que les restaba «energías para progresar por sí mismos»; además, desconfiaban, con razón, «de los mestizos y blancos». ${ }^{38}$ Por ello, el problema de la educación del indio resultaba sin duda una tarea muy compleja. Para su resolución, había que recurrir a métodos especiales que tomaran en cuenta aspectos sociales, económicos, morales, espirituales e incluso físicos. Los fondos públicos para atacar el problema eran muy escasos. La cooperación vecinal y la organización económica de la escuela resultaban por lo tanto indispensables. Las escuelas habrían de establecerse en lugares cuya población indígena fuera mayor a 60\% y en donde existieran al menos 40 alumnos. Como regla general la Casa del Pueblo no debería funcionar ni «en cabeceras» ni en "poblaciones de importancia», ya que no se buscaba quitar a las «autoridades locales su derecho y obligación de sostener planteles educativos». ${ }^{39}$

Para Corona, principal impulsor de la Casa del Pueblo, el objetivo central de la dependencia a cargo (DECI) era «el mejoramiento de las razas autóctonas»; se trataba de «impulsar el desenvolvimiento integral, la conservación», el «desarrollo y perfeccionamiento» de las industrias indígenas, así como «la implantación de nuevas actividades» productivas considerando «los productos naturales» de cada región. De esa forma sería posible tanto el mejoramiento cultural como el bienestar económico

\footnotetext{
${ }^{38}$ Corona, «Informe que rinde el Jefe del Departamento de Cultura Indígena al ciudadano Secretario de Educación Pública, relativo a las labores desarrolladas en el segundo semestre de 1923 y primer trimestre de 1924», 393.

${ }^{39}$ Corona, «Informe que rinde el Jefe del Departamento de Cultura Indígena al ciudadano Secretario de Educación Pública, relativo a las labores desarrolladas en el segundo semestre de 1923 y primer trimestre de 1924», 401. Sobre La Casa del Pueblo existe varios trabajos importantes. Entre otros, véase Katherine M. Cook, La casa del pueblo, un relato acerca de las escuelas nuevas de acción en México (México: SEP, 1932); Joseph W. Stanley, La casa del pueblo: México Experiments in Rural Education (Tesis doctoral, Stanford University, 1948); Gonzalo Aguirre Beltrán, Teoría y práctica de la educación indígena (México: SEP70, 1973); Engracia Loyo, La casa del pueblo y el maestro rural (México: Ediciones El Caballito/SEP, 1984).
} 
de los indígenas. En especial, había que promover las artesanías locales, así como «los primitivos tejidos» fabricados por los habitantes Era fundamental lograr que tales productos fuesen valorados, tanto en México como en el extranjero. El departamento a su cargo estudiaría los mejores métodos para perfeccionar la elaboración de las artesanías indígenas y las estrategias adecuadas para ampliar el mercado. Era fundamental contar con el apoyo de las autoridades de las diversas regiones étnicas con el objetivo de colectar los "productos industriales genuinamente indígenas», además de otros productos «animales, vegetales y mineras». Una de las estrategias para lograr esos propósitos era el establecimiento de un museo en la Ciudad de México en el que fuesen expuestos todos esos productos, en el cuál habrían de montarse exposiciones fotográficas que lograran captar «las características raciales y sociales de la raza indígena», así como de sus medios de vida. ${ }^{40}$

El nombre de las escuelas rurales, la Casa del Pueblo, era sin duda muy significativo al representar el «espíritu» que la SEP buscaba imprimir a la educación pública. Sin pretender ser los creadores de «nuevas doctrinas pedagógicas», dicha institución suponía «modificaciones profundas» en relación con «la organización y métodos de enseñanza de las escuelas comunes y corrientes». Según Corona, esos cambios respondían «al conocimiento real» acumulado por varios años sobre «las necesidades educativas» de los campesinos. Las Casas del Pueblo, diseñadas para «la cultura de los indígenas», representaban una forma de educación que podría "aplicarse con éxito seguro a todas las escuelas rurales del país», independientemente de la raza y de la condición étnica de los estudiantes. Corona estaba seguro de que el indígena no era «inferior al blanco o al mestizo»; tampoco era «un elemento refractario» a la «cultura». ${ }^{41}$

La Casa del Pueblo constituía una «escuela para la comunidad» y una «comunidad para la escuela». En primer lugar, se trataba de una «nueva escuela con una nueva idea directriz»; en ella no sólo se enseñaban «las primeras letras y las operaciones fundamentales de aritmética»; al mismo tiempo constituía «una nueva idea de luchar por la vida» y de

\footnotetext{
${ }^{40}$ Enrique Corona, «Informe que rinde el Jefe del Departamento de Educación y Cultura Indígena al Ciudadano Secretario de Educación Pública», 405.

${ }^{41}$ Corona, «Informe que rinde el Jefe del Departamento de Educación y Cultura Indígena al Ciudadano Secretario de Educación Pública», 393.
} 
incrementar la producción «con menor esfuerzo» físico. En segundo lugar, buscaba «congregar a todos los miembros de la comunidad», eliminando los conflictos y enemistades entre grupos, promoviendo relaciones de cooperación y colaboración para la resolución de problemas locales y regionales. En tercer término, la Casa del Pueblo buscaba establecer "vínculos de fraternidad y solidaridad entre los miembros de la especie humana", construyendo un nuevo concepto de la existencia en el que el amor a los semejantes era fundamental. ${ }^{42}$

Las nuevas escuelas buscaban diseminar «en aldeas y lugarejos, sólidas nociones de interés local, nacional y mundial». En ella no solo habrían de generarse nuevas «ideas sobre la manera de promover el bienestar personal», sino también propuestas y proyectos para «levantar el ser social, intelectual y moral» de quienes tuvieran «hambre y sed de justicia». La higiene, la «ética social», además de «las virtudes cívicas» y todo aquello que promoviera la constitución «de una humanidad mejor» sin ningún tipo de "prejuicio político ni religioso», constituían otros objetivos específicos y fundamentales. La Casa del Pueblo era también un centro de cultura que no se limitaba a atender a la población infantil; por el contrario, constituía un espacio que debía extender su influencia a toda la población, estableciendo «una corriente de entendimiento y de cooperación entre el hogar y la escuela». Otra característica fundamental es que la educación estaría "siempre dentro del campo de la experimentación» y para ello realizaría prácticas en diferentes espacios, como el jardín, las huertas, los campos de cultivo, los establos, el mercado, lugares todos en donde el maestro enseñaría nociones de vida y de trabajo. Los alumnos no sólo aprenderían a leer, escribir, contar, sino que habrían de conocer la naturaleza, siendo capaces de observarla e interpretarla a partir de la experiencia. ${ }^{43}$

La transformación que el DECI buscaba llevar a cabo no podía realizarse de la noche a la mañana. De hecho, las escuelas rurales, para constituirse en verdaderas Casas del Pueblo, debían de cumplir numerosos requisitos y superar múltiples obstáculos. Muchas escuelas no contaban

\footnotetext{
${ }^{42}$ Corona, «Informe que rinde el Jefe del Departamento de Educación y Cultura Indígena al Ciudadano Secretario de Educación Pública», 394-395.

${ }^{43}$ Corona, «Informe que rinde el Jefe del Departamento de Educación y Cultura Indígena al Ciudadano Secretario de Educación Pública», 395.
} 
con campos para el cultivo, ni gallineros, ni establos, ni semillas para sembrar; sin embargo, existían bases para ser optimistas, como el hecho de que en general los vecinos estaban cooperando. Corona calculaba que eran necesarios entre tres a cuatro años para que el proyecto de la Casa del Pueblo diera sus primeros resultados. Era indispensable comenzar "por formar entre los alumnos y otros miembros de la colectividad» nuevos hábitos; había que desterrar una forma de «idiosincrasia propia» de los habitantes rurales que inhibía la necesidad de prosperar y la búsqueda de «mayor bienestar». En otras palabras, había que desterrar la apatía. ${ }^{44}$

Para que el indígena dejara de ser un ser mecánico, no sólo tenía que aprender a leer y escribir; al mismo tiempo existía la necesidad de llevar a cabo varias reformas sociales cuyo objetivo principal era redimirlo, elevándolo «a la categoría de hombre». Las escuelas habrían de convertirse en «verdaderos centros de educación». Con el propósito de incentivar la convivencia social y la armonía, la Casa del Pueblo tenía que ser un espacio para la celebración de reuniones sociales. Una vez al mes, en la misma mesa, se sentarían a departir alumnos, padres de familia y maestros. En esas reuniones los profesores narrarían cuentos y desarrollarían temas históricos; eran también espacios para el intercambio de ideas sobre las necesidades de la comunidad y la forma de mejorar las condiciones de vida, como «el perfeccionamiento de los cultivos» o "la procreación y selección de animales domésticos». Se recomendaba realizar pláticas de carácter cívico; sin embargo, dadas las limitaciones presupuestales, el maestro misionero y del maestro rural habrían de jugar un papel fundamental. Ellos tenían que promover la cooperación de los vecinos para la construcción de gallineros y corrales. Esa actividad implicaba «despertar el espíritu de... asociación y el deseo de ayudar al país en la resolución de sus problemas». ${ }^{45}$

Tomando en cuenta las características de la localidad y la región, la Casa del Pueblo debía promover diversas actividades y conocimientos prácticos. En cuanto a las pequeñas industrias, los maestros habrían de

\footnotetext{
${ }^{44}$ Corona, «Informe que rinde el Jefe del Departamento de Educación y Cultura Indígena al Ciudadano Secretario de Educación Pública», 395.

${ }^{45}$ Corona, «Informe que rinde el Jefe del Departamento de Educación y Cultura Indígena al Ciudadano Secretario de Educación Pública», 396.
} 
promover la apicultura, avicultura, sericultura y crianza de varios tipos ganado, además del envasado de frutas, legumbres y cultivo de flores. La promoción de industrias locales, como la confección de objetos elaborados con barro, mimbre, tule, otate, carrizo, palma o hule, era fundamental. En cuanto a los oficios habría que promover la carpintería, la curtiduría o la jabonería. Para las niñas, de manera específica, era importante incluir cursos de economía doméstica con temas de remiendo, zurcido, corte y confección de ropa sencilla; no podían faltar clases de cocina para la elaboración de sopas de pastas, recetas con legumbres y platillos que incluyeran distintas clases de carnes y vegetales. Habrían de incluirse clases de dibujo vinculados a trabajos manuales. Las excursiones constituían un elemento clave para fomentar la observación de distintos procesos, como la influencia del sol y de la luna en la naturaleza, las características geográficas locales e incluso el cuidado de animales. Para la adquisición de hábitos de higiene personal debían incluirse charlas sencillas en relación con el cuidado y la limpieza de «la piel, el pelo, la boca, la nariz, el oído y los ojos». ${ }^{46}$

El programa de estudios de la Casa del Pueblo era de dos años y comprendía dos temas fundamentales: lengua nacional y aritmética. En pueblos en los que se hablara únicamente lengua indígena, durante el primer año la enseñanza del castellano constituiría un aspecto central. El aprendizaje de la lectura y la escritura serían desde luego aspectos de primera orden. Además, dentro de la materia de lengua nacional se incluían «conversaciones sobre asuntos propios de la Casa del Pueblo, del hogar o de la localidad». La narración de cuentos vinculados a la vida real, además de la enseñanza de recitaciones simples y de composiciones, monólogos y diálogos, constituían estrategias fundamentales de aprendizaje. Copiar y dictar representaban prácticas claves para ejercitar la escritura. En cuanto al programa de aritmética se promovía el «conocimiento intuitivo» de números y de «cálculos objetivos, empleando las cuatro operaciones... con los números del 1 al 20». Luego se realizaban ejercicios de cálculos mentales y escritos con las operaciones básicas: sumas, restas, multiplicaciones y divisiones. Una vez concluida esa etapa, seguía la enseñanza de los quebrados. Otro tema importante era el «conocimiento práctico ${ }^{46}$ Corona, «Informe que rinde el Jefe del Departamento de Educación y Cultura Indígena al Ciuda-
dano Secretario de Educación Pública», 397-398. 
de las monedas mexicanas de cobre, bronce, níquel, plata y oro", además medidas como el metro, el decímetro y el centímetro. ${ }^{47}$

Durante el segundo año, como parte del programa de lengua nacional, se realizaban «ejercicios sistemáticos para perfeccionar los conocimientos adquiridos en el primer grado sobre el idioma castellano». Eso incluía la lectura de fragmentos de libros, cuentos o noticias de periódicos, así como ejercicios de reflexión sobre el contenido de los mismos, ya fuera de forma escrita o verbal. Se incluían ejercicios de «redacción de cartas, recados y órdenes de uso común y corriente», además de ejercicios de caligrafía, así como las reglas básicas de ortografía. Las reuniones sociales constituían momentos adecuados para enseñar algunas composiciones sencillas en verso o en prosa, así como algunos monólogos o diálogos. En la materia de aritmética era fundamental realizar ejercicios prácticos que implicaran la utilización de operaciones básicas con números enteros y decimales; además de ampliar los conocimientos sobre sumas y restas con quebrados con denominador común, y de ejercicios prácticos que implicaran la utilización de metros, decímetros y centímetros. Otro tema importante era la conversión de varas a metros y de libras a kilos. Sin duda era fundamental que «todos los cálculos aritméticos» estuvieran «en íntima relación con los asuntos o cuestiones de la vida real». ${ }^{48}$

Junto a las actividades escolares, la Casa del Pueblo debía considerar otras experiencias educativas como las excursiones a fábricas o pequeñas industrias, así como visitas a lugares en donde existieran actividades y «medios de vida». Era importante utilizar «exhibiciones cinematográficas, como medio de propagar la cultura agrícola, industrial, social y estética de los alumnos». Resultaba indispensable hacer énfasis en el «desarrollo de los hábitos de higiene», no sólo entre los alumnos, sino en la población en general; no podía faltar la organización de grupos de deporte "para la práctica de todo tipo de juegos y competencias atléticas», fomentando incluso «deportes peculiares de cada región». ${ }^{49}$

\footnotetext{
${ }^{47}$ Corona, «Informe que rinde el Jefe del Departamento de Educación y Cultura Indígena al Ciudadano Secretario de Educación Pública», 398.

${ }^{48}$ Corona, «Informe que rinde el Jefe del Departamento de Educación y Cultura Indígena al Ciudadano Secretario de Educación Pública», 399-400.

${ }^{49}$ Corona, «Informe que rinde el Jefe del Departamento de Educación y Cultura Indígena al Ciudadano Secretario de Educación Pública», 400.
} 
Todas las actividades, tanto físicas, como estéticas o intelectuales, tenían como propósito formar «hombres libres, de iniciativa» además de «prácticos». El ideal era crear seres con sentimientos bien definidos de responsabilidad, con "pleno dominio de sí mismos», y con una "firme voluntad» de colaboración «con todos los demás hombres, a fin de labrar una existencia placentera para sí... y para los otros miembros de la colectividad». Aun cuando la moral y la formación del carácter eran aspectos que se consideraban fundamentales, no se impartirían en una clase específica y en un tiempo determinado conforme a un programa establecido de manera rígida; por el contrario, era algo que debía estar presente en todas las actividades impulsadas por la Casa del Pueblo. ${ }^{50}$

Los maestros necesariamente tendrían que considerar las circunstancias locales para diseñar sus estrategias educativas, puesto que en las zonas rurales el trabajo de los niños (en el campo) y de las niñas (en la casa) era fundamentales para la reproducción de la familia campesina. En otras palabras, resultaba indispensable impartir «la educación de acuerdo con las actividades propias de la región y las condiciones económicas de los habitantes». La distribución del tiempo y las actividades constituían puntos cruciales. Había que distribuir las actividades en un máximo de siete horas. En algunas épocas el año, cuando las actividades agrícolas demandaban mayor tiempo de trabajo de los infantes, las actividades intelectuales no debían suspenderse totalmente; por el contrario, había que buscar la forma de continuar desarrollándolas, aunque fuera en «su más mínima expresión». El maestro debía aprovechar esas coyunturas para recolectar material para sus clases, mejorar las condiciones físicas de la escuela, como el arreglo de los anexos o la construcción de lo que fuera necesario. Había que buscar un punto medio, evitando el riesgo de caer en el extremo de una «libertad irracional», puesto que la acción de la Casa del Pueblo tenía que ser cotidiana, «disciplinada, regularizada, sistemática y progresiva», tanto en sus «trabajos intelectuales», como en sus actividades mecánicas. ${ }^{51}$

\footnotetext{
${ }^{50}$ Corona «Informe que rinde el Jefe del Departamento de Educación y Cultura Indígena al Ciudadano Secretario de Educación Pública», 400.

${ }^{51}$ Corona, «Informe que rinde el Jefe del Departamento de Educación y Cultura Indígena al Ciudadano Secretario de Educación Pública», 400-401.
} 
En cuanto a las prácticas agrícolas, la SEP estableció varios lineamientos. En el primer grado se estudiaba el tipo de suelos, los instrumentos de labranza, las formas de preparar la tierra para el cultivo, la germinación de semillas, el tipo de siembras, las labores de conservación y técnicas para cosechar. En el segundo año se analizaban temas como transporte, almacenamiento de los productos, empaques, plagas y enfermedades, abonos y campos de experimentación. Un aspecto crucial se vinculaba al trabajo social asociado con «las mejoras agrícolas de la localidad» como la construcción de caminos rurales, "los detalles físicos del terreno y la situación económica de los habitantes». ${ }^{52}$ En el boletín de la SEP fueron publicados a manera de ilustración algunos ejemplos para que los maestros llevaran a cabo sus enseñanzas agrícolas. En el segundo año el profesor debía reforzar lo aprendido a lo largo del primer ciclo, haciendo énfasis en el aspecto económico. Mientras que en el primero ciclo las clases se vinculaban a las condiciones de la localidad, el ciclo de cultivo, la preparación de la tierra, la selección de semillas, entre otros temas, en el segundo ciclo era importante enfatizar la cuestión de los costos, incluyendo variables sobre el tiempo y el dinero. ${ }^{53}$

\section{EDUCACIÓN RURAL EN EL CALLISMO}

El sentido de la educación rural promovida por la SEP durante el gobierno de Plutarco Elías Calles (1924-1928) adquiere matices significativos que marcaron algunas diferencias en relación con su antecesor, Álvaro Obregón. A juicio de Calles, México requería de una población «más homogénea y más armónica». Resultaba indispensable mejorar «las grandes colectividades» del país, es decir, «las masas campesinas, obreras e indígenas.» Un elemento clave era lograr «su incorporación plena a la vida civilizada». Junto al reparto agrario, que permitiría el incremento de la producción agrícola y la «liberación económica» del campesino, «la educación de la población rural del país» habría de constituir, según Calles, otro de los elementos básicos de su administración. En su plan de gobierno se incluía la consolidación de los derechos de los trabajadores,

\footnotetext{
${ }^{52}$ Corona, «Informe que rinde el Jefe del Departamento de Educación y Cultura Indígena al Ciudadano Secretario de Educación Pública», 412.

${ }^{53}$ Corona, «Informe que rinde el Jefe del Departamento de Educación y Cultura Indígena al Ciudadano Secretario de Educación Pública», 414.
} 
tanto en las ciudades como en «los centros industriales». Se buscaba, en suma, «equidad y justicia para todas las clases sociales». Con todo, dado que la mayor parte de la población en México vivía en el campo, «el problema educacional de las masas rurales» merecía atención especial. No sólo se trataba de abatir el analfabetismo; era al mismo tiempo fundamental lograr «un desarrollo armónico» de la población indígena. Esa enorme masa de personas tenía que «incorporarse plenamente a la civilización». Hasta donde las finanzas lo permitieran, la expansión de la escuela rural sería una de las prioridades de aquella administración. ${ }^{54}$

Según el Secretario de Educación Pública, Manuel Puig Casauranc, pese a todos los esfuerzos realizados hasta ese momento para incorporar a «las grandes colectividades campesinas y de la raza indígena a una vida propiamente civilizada», los resultados eran totalmente insatisfactorios. Ante tales circunstancias hizo un llamado a «los mexicanos de buena voluntad», preocupados por el mejoramiento colectivo, a cooperar con el gobierno federal encabezado por el presidente Elías Calles. Resultaba imprescindible que los ciudadanos cuya concepción de patria fuese «correcta», sacudieran su indiferencia y se sumaran al esfuerzo de las autoridades federales. ${ }^{55} \mathrm{Si}$ bien era evidente que la universidad constituía una pieza clave para la construcción del conocimiento científico, el esfuerzo educativo del gobierno federal haría énfasis en la educación básica, no sólo de la población urbana, sino sobre todo de la población rural, es decir, de «las grandes masas de campesinos, mestizos e indígenas». ${ }^{56}$

La población rural y la urbana eran diferentes entre sí y por ello resultaba indispensable crear programas específicos para los alumnos de las ciudades y del campo. En los dos casos, un punto básico era la generación de conocimientos científicos para después proceder a la práctica. Ningún programa podía tener éxito sin el conocimiento de la población escolar, de las características y las problemáticas de los educandos. Así como sobre la población urbana era fundamental «establecer y ensanchar un departamento especial de investigación» social que mostrara las caracte-

${ }^{54}$ Plutarco E. Calles, «Las ideas del Señor Presidente de la República en Materia de Educación», Boletín de la Secretaría de Educación Pública, III (8), (1925): 7.

${ }^{55}$ Manuel Puig, «Mensaje enviado por radio desde la estación de la Secretaría de Educación Pública, el 6 de diciembre de 1924», Boletín de la Secretaría de Educación Pública, III (8), (1925): 15,

${ }^{56}$ Puig, «Mensaje enviado por radio desde la estación de la Secretaría de Educación Pública, el 6 de diciembre de 1924», 16. 
rísticas generales de los habitantes urbanos, era indispensable establecer un departamento específico cuyo objetivo fuese el «estudio científico de la población rural». Dicha instancia habría de analizar los «antecedentes antropológicos» de los habitantes del campo, su historia y sus problemáticas contemporáneas. Todo ese conocimiento sería de utilidad para un fin práctico: la incorporación de las masas rurales a la civilización. ${ }^{57}$

Uno de los grandes problemas que la SEP enfrentaba era la carencia de maestros rurales bien preparados. Ni de la Universidad Nacional ni las Escuelas Normales estaban egresando los maestros que las escuelas rurales necesitaban. Un aspecto fundamental era la formación de profesores que hablaran la lengua indígena de la región donde habrían de enseñar. La experiencia mostraba, por otro lado, que los maestros formados en esas instituciones no estaban dispuestos a desplazarse a pequeñas localidades rurales para ejercer su profesión y educar a los habitantes del campo. De hecho, los profesores con el perfil adecuado se negaban a abandonar la ciudad; no existían maestros dispuestos a participar en la cruzada para formar patria. Bajo tal circunstancia la secretaría se veía obligada a contratar a profesores urbanos como maestros rurales, quienes no sólo carecían de «la preparación mental» adecuada, sino que no mostraban ningún interés por el campo y sus problemáticas sociales. En tanto se lograba la preparación de una cantidad «suficiente de profesores para escuelas rurales», una alternativa era reclutar a individuos «de buena voluntad» que conocieran «las necesidades del medio y de la población escolar». ${ }^{58}$

Con el propósito de unificar culturalmente a la población y crear «aspiraciones análogas» entre todos los mexicanos, la SEP creó dos nuevos departamentos. Uno de Antropología y otro de Escuelas Rurales e Incorporación Cultural Indígena (DERCI). El primero tuvo como objetivo central analizar a la población rural del país mediante procedimientos científicos, para elaborar los programas de la SEP que estarían dirigidos a «las grandes masas campesinas», tanto indígenas como mestizas. Entre varios temas, dicha instancia investigaría «las causas por las que

\footnotetext{
${ }^{57}$ Puig, «Mensaje enviado por radio desde la estación de la Secretaría de Educación Pública, el 6 de diciembre de 1924», 17.

${ }^{58}$ Puig, «Mensaje enviado por radio desde la estación de la Secretaría de Educación Pública, el 6 de diciembre de 1924», 19.
} 
la población indígena» pudo alcanzar «un alto desarrollo integral» en tiempos pasados, es decir, antes de la conquista, así como las razones por las cuales los indígenas se convirtieron en un problema. ${ }^{59}$ Ese trabajo, que venían realizando Manuel Gamio y su equipo desde la Secretaria de Agricultura Fomento, fue transferido a la nueva dependencia a partir del primero de enero del año de 1925; sin embargo, el célebre antropólogo entró en contradicción con Manuel Puig al denunciar problemas de corrupción, por lo que pronto abandonó la SEP y viajó a Chicago. ${ }^{60}$

Pese a los conflictos, el Departamento de Antropología continuaría estudiando las «ideas éticas, estéticas, religiosas», así como los «idiomas, dialectos, hábitos, costumbres, aspiraciones y necesidades intelectuales y económica de la población indígena en épocas pasadas»; estudiaría también el comercio, la industria, la agricultura, la distribución geográfica, las habitaciones y la indumentaria. Esos conocimientos, aunados, a los datos proporcionados por el estudio de la población contemporánea, permitirían a la SEP «deducir, por procedimientos lógicos... los medios propicios para procurar la mejoría material e intelectual de las diversas agrupaciones nacionales». En relación con el estudio de la población contemporánea el Departamento de Antropología comprendía cuatro áreas: I. Antropología y eugenética; II. Estudios Sociales, Etnográficos y Lingüísticos; III. Censo y Legislación Indígena; IV. Exposiciones Etnográficas. ${ }^{61}$

Por su lado, el Departamento de Escuelas Rurales e Incorporación Cultural Indígena tomaría en cuenta el conocimiento científico generado por el Departamento de Antropología para su desempeño. La meta era crear 4.000 escuelas rurales, instituciones en las cuales los infantes del campo no sólo recibirían «instrucción primaria elemental», sino que aprenderían además «a localizar materias primas», tanto vegetales como «animales y minerales» con el objetivo de «transformarlas en productos comerciales de venta efectiva y de útil consumo doméstico». Esos conocimientos y habilidades habrían de extenderse a la población adulta

59 «Educación Rural, Departamento de Antropología y de Escuelas Rurales e Incorporación Cultural Indígena», Boletín de la Secretaría de Educación Pública, III (8), (1925): 26

${ }^{60}$ Ángeles González, Manuel Gamio, una lucha sin final (México, UNAM, 1987), 79-81.

${ }^{61}$ «Educación Rural, Departamento de Antropología y de Escuelas Rurales e Incorporación Cultural Indígena», Boletín de la Secretaría de Educación Pública, III (8), (1925): 26-27. 
«mediante cursos especiales», o a través de conferencias sencillas. Las enseñanzas de teoría rudimentaria habrían de apoyarse en «pequeños textos especiales». ${ }^{62}$

\section{EL PROBLEMA RURAL}

Para Gregorio Torres Quintero, la Escuela Rural era la institución destinada a la educación de los habitantes cuya sobrevivencia dependía "de los productos de la agricultura»; sin embargo, existían varias confusiones en cuanto a su definición, en parte, derivadas de las diversas condiciones sociales de los pueblos y rancherías. ${ }^{63}$ La diferencia entre educación rural y educación urbana no era un tema menor dado que en la década de 1920 tres cuartas partes de la población en México vivían en el campo; con todo, existían diversas confusiones que daban paso a equívocos en cuanto a las estrategias educativas y los programas escolares. No obstante, la "pobreza nacional», la producción agrícola era superior en valor a la producción minera, que además estaba en manos de capitales extranjeros, incluido el petróleo. Con todo, México no era autosuficiente en materia de producción de alimentos, siendo preciso importar ganado y maíz, además de "mantequilla y huevos». Bajo dichas circunstancias, era un «deber patriótico intensificar la producción agrícola». Para resolver esa problemática, un aspecto básico era lograr una «educación adecuada». De ahí se desprendía «la necesidad de una escuela rural organizada» que tomara en cuenta tanto «las necesidades espirituales como económicas» de los campesinos. Gregorio Torres Quintero no tenía duda en cuanto a la necesidad de contar con escuelas rurales en todos los niveles. ${ }^{64}$

Si bien el discurso la SEP establecía una diferencia entre educación rural y educación urbana, en la práctica, la distinción no era para nada evidente. Parte del problema era la falta de claridad en relación con «los

\footnotetext{
62 «Educación Rural, Departamento de Antropología y de Escuelas Rurales e Incorporación Cultural Indígena», 27.

${ }^{63}$ Gregorio Torres Quintero (1866-1934), originario de Colima, estudió en la Escuela Nacional de Maestros, graduándose en 1891. Fue un activo promotor de la escuela pública, laica y gratuita en México. Colaboró en la SEP, jugando un destacado papel en educación rural durante el gobierno de Calles.

${ }^{64}$ Gregorio Torres, «Orientaciones y Organizaciones de las Escuelas Rurales», Boletín de la Secretaría de Educación Pública, IV (2), (1925): 200.
} 
fines de una y los fines de la otra». En ambos casos, era fundamental que los niños comprendieran tanto «la vida individual» como la «vida social del medio en el que se desenvolvían». Los infantes tenían que ser adiestrados de tal manera que al convertirse en adultos se adaptaran a su ambiente. El ciudadano del campo tenía que ser «rural en sus deseos, rural en sus empresas y propósitos»; debía ser a la vez alguien que amara la tierra y a su patria. El buen campesino tenía que estar compenetrado en la vida rural, de tal forma que la ciudad no fuese un foco de atracción, pese a sus encantos y luces. ${ }^{65} \mathrm{La}$ escuela rural no sólo debía de enseñar a leer, escribir y contar; tenía al mismo tiempo que ser capaz de crear sujetos inteligentes con la habilidad de «interpretar mejor sus funciones» en relación con la explotación de la tierra, haciendo rendir al suelo sus más ricos frutos; al mismo tiempo tenía generar individuos que no solo mantuvieran en su «alma un acendrado afán por la vida rústica», sino que al mismo tiempo los acostumbrara a «emplear su ocio en beneficio propio y de la comunidad». Al mejorar la vida individual del sujeto, se produciría al mismo tiempo un beneficio para la comunidad en relación con la salud física, moral e incluso social. En resumen, afirma Quintero, la educación rural tenía que lograr que los campesinos fueran «mejores rancheros y mejores ciudadanos». ${ }^{66}$

Era indispensable ofrecer una preparación adecuada a los maestros rurales. Ello implicaba que el profesor comprendiera las necesidades de la vida rural; además de ser culto y práctico, el educador tenía que ser alguien que estuviera dispuesto a permanecer en la comunidad, como cualquier otro vecino, mostrando disposición para colaborar por el bienestar de los habitantes locales. Por lo general, los maestros solían quedarse en los pueblos unos cuantos días, para después salir de ahí y abandonar la escuela y la comunidad. Ese era un problema general, no sólo de México, sino también de otros países, como Estados Unidos, según el testimonio de un agricultor estadunidense que Torres cita en su trabajo. Un aspecto crucial era que el «maestro se convirtiera en vecino del lugar para tomar parte en la discusión de los problemas rurales» y contribuir a su resolución; debía de convertirse en líder y en un emprendedor que tomara la

65 Torres, «Orientaciones y Organizaciones de las Escuelas Rurales», 201.

66 Torres, «Orientaciones y Organizaciones de las Escuelas Rurales», 202. 
iniciativa de todo aquello que resultara benéfico para los niños y la comunidad. El buen maestro no podía ni debía limitar su trabajo al aula. ${ }^{67}$

A pesar de que en algunas comunidades rurales existían escuelas desde la época colonial, muchas localidades permanecían en el atraso; los niños, al terminar sus estudios, pronto olvidaban lo que habían aprendido en las aulas por el hecho de que los conocimientos adquiridos nada tenían que ver con su vida cotidiana, como escribir o hablar español. Aquella escuela rural no respondía a «las necesidades reales» de la población del campo; además, los maestros, muy mal preparados, no lograron comprender "su misión», sobre todo por la falta de conocimientos en relación con «los fenómenos sociológicos y económicos» de las comunidades en las que trabajaban. El buen maestro rural no podía limitar sus conocimientos y enseñanzas a las materias que se impartían en las escuelas urbanas. Los profesores rurales debían prepararse en al menos tres aspectos. Primero, tenían que conocer fundamentos de economía y sociología rural, herramientas que les permitirían comprender tanto los problemas como las «necesidades de la vida rural». Sólo así el profesor estaría en condiciones de convertirse en «director y consejero de la comunidad». En segundo término, para tener la capacidad de transformar la «vieja escuela rural» y convertirla en la escuela que exigía la agricultura moderna, el profesor habría de comprender de manera amplia «la organización escolar». Por último, resultaba imprescindible ofrecer materias que permitieran aprovechar mejor la vida. ${ }^{68}$

Torres afirmaba: «los programas de las escuelas rurales deben basarse en lo que el campesino y su mujer deben conocer teniendo en cuenta la etapa social de cada agrupación». No era lo mismo una comunidad rural dedicada a la caza o recolección y que utilizaba el arco y la flecha, que una comunidad donde la producción agrícola se llevara a cabo utilizando arados o tractores modernos; sin embargo, pese a las diferencias entre los muy diversos tipos de comunidad, existían elementos compartidos en cuanto a la educación rural. El primero se vincula a «la salud y felicidad personales», esto es, al "plano humano». Un segundo elemento era «la preparación de los miembros de la familia para el buen cumplimento de sus derechos y deberes cívicos y sociales»; finalmente, estaban los co-

\footnotetext{
${ }^{67}$ Torres, «Orientaciones y Organizaciones de las Escuelas Rurales», 202.

68 Torres, «Orientaciones y Organizaciones de las Escuelas Rurales», 203.
} 
nocimientos prácticos indispensables para mejorar la vida mediante la explotación inteligente del medio ambiente y el desarrollo de industrias agrícolas. ${ }^{69}$

El conocimiento del contexto social, económico y cultural constituía un requisito imprescindible para que la escuela respondiera «a las necesidades del medio». Quintero estaba convencido de que la «vida en el campo y en las comunidades» merecía ser analizada en términos sociológicos. La gran diversidad de contextos y formas de comunidad se reflejaba en una amplia variedad de formas de organización y de necesidades locales. En el campo mexicano estaban representadas todas «las etapas de la civilización». A pesar de dicha heterogeneidad, algo en común era el hecho que todas esas poblaciones vivían principalmente de la explotación de la tierra. Un aspecto central eran las vías de comunicación. Para llevar a cabo una producción agrícola industrial eficiente era indispensable contar con carreteras «rápidas y seguras». Muy pocas eran las regiones y las localidades «adelantadas»; en la mayor parte del territorio existían "costumbres casi primitivas». Los indios utilizaban la coa para sembrar maíz; había casos en los que se utilizaban yuntas movidas por bueyes y arado egipcio. En regiones «más privilegiadas» se utilizaba «el arado de acero tirado por mulas o caballos». El tractor, representaba el instrumento más avanzado para la producción agrícola. En un extremo existían «el sembrador» que cosechaba para sostener a su familia; en el otro, se encontraba el agricultor que producida para el mercado nacional e incluso para la exportación. La primera era una economía «empírica y primitiva»; la segunda «científica y moderna». ${ }^{70}$

Debido a la enorme heterogeneidad social, las condiciones de educabilidad eran distintas. En las localidades donde la producción se llevaba a cabo con métodos «primitivos» y el producto se destinaba al consumo local, la familia resultaba un «elemento de educación muy eficaz». El padre enseñaba a sus hijos los métodos rudimentarios de labranza «así como otras industrias productivas no muy complicadas»; por su parte, la madre instruía a sus hijas en aspectos básicos sobre «el cuidado del hogar» y en otras actividades como «el hilado y tejido». En esos casos, la familia constituía el principal espacio social de ajuste al medio. Algo

${ }^{69}$ Torres, «Orientaciones y Organizaciones de las Escuelas Rurales», 204.

70 Torres, «Orientaciones y Organizaciones de las Escuelas Rurales», 204. 
similar sucedía en localidades donde la familia buscaba «obtener una modesta sobreproducción» destinada a la venta en el mercado. En contraste, en regiones donde se practicaba la agricultura comercial, las condiciones eran diferentes. El hijo de un ranchero no podía limitar sus conocimientos a lo que su padre le podía enseñarle; de hecho, necesitaba el apoyo de especialistas y del aprendizaje «de prácticas agrícolas más ilustradas». Con estos elementos, Quintero argumenta sobre la necesidad de ser flexible en cuanto a las enseñanzas de la educación rural, creando distintas escuelas y diversas jerarquías, "desde las más humildes hasta las más encumbradas en la escala pedagógica». ${ }^{71}$

Quintero sabía muy bien de la enorme heterogeneidad en cuanto al contexto social y económico de las diversas comunidades dispersas a lo largo y ancho del territorio nacional; sin embargo, al mismo tiempo, estaba convencido, como muchos otros intelectuales y políticos, que «los medios rurales» padecían de "deficiencias económicas y sociológicas». Dada la importante migración del campo a la ciudad, "la agricultura» enfrentaba problemas significativos. La disminución de la producción agrícola no sólo significaba «una mengua de sangre en la vida nacional», sino también «en la raza». Puesto que en México no existían estudios sobre ese proceso, no se sabía con precisión si la población rural estaba disminuyendo o aumentando. De lo que no había duda era el hecho de que las revoluciones habían propiciado el desplazamiento de población rural a espacios urbanos, incluso hacia el extranjero, en búsqueda de seguridad y empleo. Dicha tendencia implicaba una «crisis agrícola e industrial» muy relevante. Era urgente reanudar el trabajo agrícola. En pocas palabras, «la vida rural» debía «renacer y encauzarse lo más rápidamente posible». La estabilidad de la población rural en el campo constituía un requisito para asegurar el futuro del país y la nación. Por ello resultaba urgente mantener una población compenetrada en la vida rural. Esa disposición hacia la vida en el campo debía ser heredada por los hijos y los hijos de sus hijos. ${ }^{72}$

El problema era considerable dado que «la vida del campo» era monótona y no «tan grata», a juicio de Quintero. ¿Qué hacer? En primer lugar, era preciso que la actividad agrícola fuese un buen negocio; en segundo

\footnotetext{
${ }^{71}$ Torres, «Orientaciones y Organizaciones de las Escuelas Rurales», 205.

72 Torres, «Orientaciones y Organizaciones de las Escuelas Rurales», 206.
} 
término, había que crear condiciones para una vida rural «atractiva socialmente»; para eso era necesario fomentar formas de recreación sana y terminar con «el aislamiento social». De otra forma, los rancheros, que por el hecho de serlo "no dejaban de tener alma en el cuerpo», corrían el riesgo de sentirse atraídos por la ciudad. El mayor problema, según Quintero, era el aislamiento físico, psicológico y sociológico. Una de las consecuencias de dicha circunstancia era «el desarrollo del individualismo» y un acendrado "espíritu de independencia», característicos de la población ranchera. Esa falta o ausencia de «trato social» los volvía «desconfiados y egoístas». Vivían temiendo siempre ser engañados por los demás. Algo similar sucedía en pueblos pequeños y aldeas. Aun cuando muchas familias vivían juntas, en la práctica permanecían aisladas. En otras palabras, no existía un sentimiento de comunidad y no cooperaban entre ellos. Incluso algunos sociólogos opinaban que el peor lugar para crear una familia era la pequeña aldea rural. ${ }^{73}$

El campo, donde los hombres se arruinaban y dislocaban, era también el espacio social en donde la escuela rural debía actuar, de forma coordinada, con otras agencias civilizadoras; la escuela debía fomentar «el desarrollo del espíritu de ayuda mutua y de cooperación social». La base de nuevas formas de convivencia y cooperación en la población rural se encontraba en «la organización de actividades de naturaleza económica» que motivaran al agricultor a "producir más y mejor», a transformar las materias primas en «manufacturas bien acabadas en el lugar mismo de su producción», y a llevar esos productos a los lugares de venta adecuados. Una vez establecida dicha base económica, sería posible fomentar otras tendencias sociales, «educativas, recreativas, morales» e incluso actividades estéticas. Luego se desarrollaría la actividad política. Si bien el proyecto parecía irrealizable, tomando en cuenta otras experiencias de pueblos europeos y los Estados Unidos, Quintero subraya que la escuela rural había dado pruebas fehacientes de ser fuerte y eficaz al estar inspirada en ideales cívicos. ${ }^{74}$

La clave de la escuela rural se encontraba en la organización social. En particular, había que atender tres aspectos fundamentales. En primer lugar, la organización material, vinculada con el edificio, los muebles y

\footnotetext{
${ }^{73}$ Torres, «Orientaciones y Organizaciones de las Escuelas Rurales», 207.

${ }^{74}$ Torres, «Orientaciones y Organizaciones de las Escuelas Rurales», 207-208.
} 
los útiles; en segundo término, «la organización intelectual o pedagógica, relativa a la selección u arreglo del programa y su presentación por medio de la enseñanza», asociados con horarios, formación de los grupos y promoción de los alumnos; finalmente la organización social propiamente dicha, es decir, la relación entre la escuela y la comunidad, por un lado, así como «las relaciones de los alumnos unos con otros y con el maestro», por el otro. Si bien las autoridades escolares habían atendido de manera sistemática los dos primeros aspectos, el tercer punto era el más problemático. Era este último aspecto donde Torres Quintero buscaba realizar su principal aporte. La relación entre escuela y comunidad era el aspecto más problemático y desatendido hasta el momento. La escuela no proporcionaba a la comunidad una forma de hacer la «vida más amplia, más feliz y más eficiente»; por su lado, la comunidad no daba «a la escuela toda la ayuda y la cooperación» que ella necesitaba. El problema se tornaba aún más complejo ya que los habitantes esperaban todo del gobierno. Esa falta de iniciativa individual convertía a México «en un pueblo sin espíritu ni aspiraciones». Según Quintero, los mexicanos, como los musulmanes, se movían «sentados en la puerta de la tienda, esperando pacientemente» a que se cumpliera «la voluntad de dios». Ante esa situación había que reflexionar sobre las causas del estancamiento «Social, moral, económico, cívico y político» de las comunidades rurales, así como proponer soluciones para despertar y sacudir el "marasmo» en el que se encontraban hundida la población rural. La escuela rural moderna debía de "transformar eficientemente» a las "comunidades rurales incorporándolas a la civilización»; debían promover el aumento y el perfeccionamiento de la producción agrícola, «base de la alimentación nacional y de la energía de la raza». ${ }^{75}$

Con matices, esa forma de percibir las cosas era compartida por muchos intelectuales y políticos. Manuel Puig Casauranc, titular de la SEP durante el gobierno de Calles escribe: «El estado de atraso que en todos los órdenes guardan las comunidades rurales de nuestro país, ha planteado al Gobierno emanado de la Revolución, el problema de la vida rural», el cual exigía de manera imperiosa ser solucionado con el propósito de que México fuera parte de los «pueblos civilizados». Además afirma que «el problema de la vida rural», entre otras cosas, se vinculaba a «cues-

\footnotetext{
75 Torres, «Orientaciones y Organizaciones de las Escuelas Rurales», 208-209.
} 
tiones de cómo hacer el suelo más productivo», de "cómo dar al campesino mayor bienestar y más comodidades», de "cómo incorporarlo a la civilización» y de "cómo hacer de la vida del campesino más grata y agradable». ${ }^{76} \mathrm{~A}$ pesar de que el mismo personaje planteaba la necesidad de "educar a los niños para la vida rural y no para la vida urbana» y subrayaba además la necesidad de una «educación diferente en su contenido y en sus tendencias entre la escuela rural y la urbana», y aun cuando para Puig resultaba indispensable establecer «un programa práctico de estudios en el que las asignaturas y actividades» fueran la expresión «fiel de las necesidades y aspiraciones de la comunidad rural», una buena proporción de las acciones del gobierno federal contradecía esa convicción o por lo menos matizaba la definición de lo que se consideraban aspiraciones populares. En efecto, existía una preocupación muy grande en torno a las necesidades locales; con todo, muchas de las expectativas del campesino iban a contra corriente de las aspiraciones de los modernistas; de hecho, los programas de desarrollo desataron numerosas manifestaciones de resistencia generando resultados diversos.

\section{EDUCACIÓN RURAL EN EL MAXIMATO}

El asesinato de Álvaro Obregón en el mes de julio de 1928 marcó el inicio de una nueva etapa en la historia política de México. Es sabido que Plutarco Elías Calles se convierte en el jefe máximo de la revolución entre 1929 y 1935. Si bien no llegó a ser tan poderoso como varios historiadores lo han señalado, tuvo la habilidad de convertirse en un «árbitro político» a nivel nacional: ${ }^{77}$ No sólo creó el Partido Nacional Revolucionario (PNR), una pieza clave en el proceso de institucionalización del nuevo sistema político mexicano; logró también convertirse en el principal dirigente político del gobierno federal a lo largo de seis años (1928-1934), una etapa en la que Emilio Portes Gil, Pascual Ortiz Rubio y Abelardo Rodríguez fungieron como presidentes de la República por períodos breves. Calles tuvo incluso capacidad de ejercer cierta influencia sobre Lázaro Cárdenas del Río durante el primer año de su administración presidencial. A lo largo del

\footnotetext{
${ }^{76}$ «Platica del Dr. J. M Puig Casauranc, Secretario de Educación Pública, a los miembros de las Misiones Culturales, del 25 de febrero de 1927», Boletín de la Secretaría de Educación Pública, XVII (5), (1927), 5.

${ }^{77}$ Jurgen Buchenau, Plutarco Elias Calles and the Mexican Revolution (USA: Rowman and Littelfield Publishers, 2007), 144.
} 
maximato hubo varios secretarios de educación pública: Ezequiel Padilla (1928-1929), Joaquín Amaro (1929-1930), Aarón Sáenz (1930), Manuel Puig Casauranc (1930-1931), Narciso Bassols (1931-1934), Eduardo Vasconcelos (1934) e Ignacio García Téllez (1934-1935). Todos ellos consideraban que la vida rural representaba un problema que era preciso resolver.

Narciso Bassols, Secretario de Educación en los gobiernos de Ortiz Rubio y Abelardo Rodríguez, impulsó algunos cambios en la agenda pública de la educación rural. ${ }^{78}$ Además del «problema» de la heterogeneidad cultura, un elemento básico de su discurso refiere a las profundas diferencias entre el campo y la ciudad. En efecto, a su juicio, lo rural y lo urbano representaban dos «sistemas intelectuales, dos doctrinas [...] independientes una de otra» y por lo mismo dos sistemas de educación diferenciados. La diversidad racial así como los antagonismos económicos, junto a un cúmulo de circunstancias políticas, explicaban esa distancia entre la ciudad y el campo. ${ }^{79}$ La historia mexicana estaba cruzada por una «trágica y vieja disputa de intereses, tendencias, fuerzas vitales e ideas» entre «ambos mundos diferenciados». Si bien la independencia fue un movimiento que involucró principalmente a la población rural, con el correr de los años, la ciudad se impuso sobre el campo. En el México independiente «el ritmo de la vida social» en el espacio rural comenzó a ser determinado por el espacio urbano; se trata de una tendencia que fue volviéndose más evidente con el paso del tiempo. Ese contraste entre ciudad y campo constituía un claro emblema de la falta de integración cultural y económica de la nación mexicana. Dicha diferencia era crucial para entender el programa de la SEP, ya que no sólo afectaba la organización de métodos pedagógicos, sino también la «estructura misma del sistema de educación». De hecho, la secretaria bajo su cargo contemplaba estrategias específicas para la educación rural y para la urbana. ${ }^{80}$ Bajo sus órdenes, la SEP tomaba en cuenta «las aspiraciones y

\footnotetext{
${ }^{78}$ Narciso Bassols, «The general program of education in Mexico; and address delivered by His Excellency the Minister of Education, Señor licenciado Narciso Bassols before the Seminar in Mexico, on July 19, 1932», Mexico: Butler Library, Columbia University, microfilm 308, Z, Box 407.

${ }^{79}$ Bassols, «The general program of education in Mexico; and address delivered by His Excellency the Minister of Education, Señor licenciado Narciso Bassols before the Seminar in Mexico, on July $19,1932 », 4$

${ }^{80}$ Bassols, «The general program of education in Mexico; and address delivered by His Excellency the Minister of Education, Señor licenciado Narciso Bassols before the Seminar in Mexico, on July 19, 1932», 5 .
} 
las necesidades de los campesinos»; el objetivo era lograr una «verdadera integración al organismo nacional» hasta alcanzar la «redención de las masas agrícolas». A juicio de Bassols, una de las consecuencias del movimiento revolucionario fue haber despertado el deseo de educación entre los habitantes del campo; por ello, el gobierno federal había creado una estrategia para satisfacer dicha necesidad. ${ }^{81}$ Para el momento en que Bassols escribe, es decir, 1932, existían ya miles de escuelas rurales distribuidas a lo largo y ancho del país. Al inicio del programa educativo en el año de 1921, recuerda, fue necesario convencer a los campesinos sobre la necesidad de construir escuelas; pese a múltiples dificultades, los indígenas contribuyeron a su creación. ${ }^{82}$ El cambio en el paisaje fue visible con el paso de los años; a juicio de aquel secretario, mientras que en muchos pueblos las iglesias se convertían en ruinas, las escuelas se multiplicaban. Esa transición no sólo hacía referencia a un cambio en el aspecto físico y material de las localidades; constituía además el emblema de un cambio psicológico de gran relevancia asociado al profundo cambio cultural que el país estaba experimentando bajo la conducción de los gobiernos revolucionarios. Bassols no tenía duda de que los campesinos depositaron su fe en la escuela; más aún, consideraba, que los habitantes del campo se habían de hecho reagrupado espiritualmente alrededor de la escuela, identificándose entre sí de una manera «fecunda y consciente», desplazando a la Iglesia como núcleo aglutinador de la población. ${ }^{83}$ La edificación de miles de escuelas en el país no hubiera sido posible sin la cooperación de los campesinos; además, los trabajadores del campo estaban recibiendo parcelas, terminando así con su antigua condición de esclavitud. ${ }^{84}$

\footnotetext{
${ }^{81}$ Bassols, «The general program of education in Mexico; and address delivered by His Excellency the Minister of Education, Señor licenciado Narciso Bassols before the Seminar in Mexico, on July $19,1932 », 6$.

${ }^{82}$ Bassols, «The general program of education in Mexico; and address delivered by His Excellency the Minister of Education, Señor licenciado Narciso Bassols before the Seminar in Mexico, on July 19, 1932», 7.

${ }^{83}$ Bassols, «The general program of education in Mexico; and address delivered by His Excellency the Minister of Education, Señor licenciado Narciso Bassols before the Seminar in Mexico, on July 19, 1932», 8 .

${ }^{84}$ Bassols, «The general program of education in Mexico; and address delivered by His Excellency the Minister of Education, Señor licenciado Narciso Bassols before the Seminar in Mexico, on July 19, 1932», 9-10.
} 


\section{CONCLUSIÓN}

Entre finales de 1922 y septiembre de 1923 el número de estudiantes en escuelas rurales se duplicó al pasar de 17,000 a 34,000 alumnos, instalándose escuelas en «lugares donde jamás había existido colegio alguno». ${ }^{85}$ Para el año de 1924, las cifras oficiales señalan la existencia de 1605 escuelas primarias, tanto urbanas como rurales, en todo el país, atendidas por 3,922 maestros. ${ }^{86}$ Durante la administración presidencial de Plutarco Elías Calles el esfuerzo Educativo creció de manera significativa. Una fuente indica que en 1924 existían 1,044 escuelas rurales en las que estaban inscritos 76,076 alumnos atendidos por 1,105 profesores, mientras que para el año de 1928 se registraban un total de 3,392 escuelas y 4,712 maestros, atendiendo a una población escolar de 284,056 alumnos. Esto significa que en ese periodo aproximado de cuatro años fueron edificadas 2,348 nuevas escuelas, siendo contratados 3,607 nuevos maestros y enrolado 207,980 alumnos. Otro dato importante para la misma etapa es que el número de inspectores pasó de 47 a 117, mientras que el presupuesto creció de 1,540,128 a 4,296,810 pesos. ${ }^{87} \mathrm{El}$ incremento en el número de inspectores y recursos públicos federales se vincula al proceso de federalización educativa. ${ }^{88}$ Por su lado, una publicación de la UNESCO indica que en el año de 1923 existían 1,023 escuelas rurales atendidas por 876 maestros con una población escolar de 50,000 alumnos; para 1930 existían 6,132 escuelas, 6,504 maestros rurales y una población escolar de 324,798 estudiantes; hacia 1938 había 17,047 maestros rurales, 683,432 alumnos y 11,248 escuelas. ${ }^{89}$

La década de 1920 es considerada como la edad de oro de la educación rural en México; sin embargo, el crecimiento del número de escuelas, de maestros y la matrícula escolar, a juicio de Moisés Sáenz, implicó

\footnotetext{
${ }^{85}$ La educación pública en México a través de los mensajes presidenciales, General Álvaro Obregón, (México: Secretaría de Educación Pública, Septiembre $1^{\circ}$ de 1923), 229, énfasis en el original.

${ }^{86}$ La educación pública en México a través de los mensajes presidenciales, General Álvaro Obregón, (México: Secretaría de Educación Pública, Septiembre 1. e 1924), 231.

${ }^{87}$ El esfuerzo educativo en México, La obra del gobierno federal en el ramo de educación pública durante la administración del presidente Plutarco Elías Calles (1924-1928), (México: Secretaría de Educación Pública, Tomo I, 1928), 22.

${ }^{88}$ Alberto Arnaut, Historia de una profesión. Los maestros de educación primaria en México, 1887-1994 (México: CIDE, 1996).

${ }^{89}$ Lloyd Huges, The Mexican Cultural Mission Programme (Paris: UNESCO, 1950), 14.
} 
múltiples problemas, retos y dificultades. ${ }^{90}$ A pesar de que varios actores e intérpretes hicieron énfasis, a lo largo del tiempo, sobre el hecho de que los profesores no debían estar involucrados en cuestiones políticas, el proceso caminó en otro sentido; de hecho, la tendencia fue a politizar la actividad del magisterio, pero no en un sentido "revolucionario», sino de control y subordinación a organizaciones corporativas. Encabezado por el poderoso líder sindical, Luis Napoleón Morones, la Confederación Revolucionaria Obrera Mexicana (CROM) hizo suyas las demandas de los maestros y la educación pública en 1924. Otra coyuntura relevante fue la constitución del Partido Nacional Revolucionario (PNR) en el año de 1929. El punto IX de la declaración de principios del PNR específica que la alfabetización de las masas, en particular de la población rural, constituía uno de sus objetivos fundamentales del nuevo partido, mismo que apoyó la construcción de nuevas escuelas rurales, tanto para niños como para adultos, así como la organización corporativa de los maestros. En la década de 1930, la sindicalización del magisterio corrió paralela a un significativo incremento de escuelas y maestros rurales.

La historia política oficial de la posrevolución plantea que la educación rural implementada por la SEP constituyó un éxito en la transformación de los habitantes del campo en ciudadanos, sobre todo en términos de los derechos sociales. Es cierto que los diferentes proyectos educativos y culturales tuvieron consecuencias socioculturales muy relevantes, como fue la difusión y socialización del sentimiento nacionalista; sin embargo, un aspecto fundamental es la tensión, siempre presente y al parecer irresoluble, entre la urgencia de atender las «necesidades locales», por un lado, y responder a las «necesidades de la nación», por el otro. Si bien en el discurso público se hizo énfasis en la premura de retomar las «necesidades» y los requerimientos de la población, en la práctica, muchos de los agentes del Estado realizaron su trabajo pensando en forjar patria, supeditando los intereses individuales al «interés general». En distintos casos, la gente del pueblo, por su «ignorancia», se «resistía» al progreso, «desvirtuando» o adaptando los designios modernizadores de los proyectos estatales. En otras palabras, las necesidades locales no necesariamente coincidían con las necesidades nacionales; más aún, en

\footnotetext{
${ }^{90}$ Alberto Arnaut, La federalización educativa en México: Historia del debate sobre la centralización y la descentralización educativa (1889-1994) (México: El Colegio de México/CIDE, 1998), 173.
} 
muchas ocasiones eran contrapuestas, sobre todo por el hecho de que estas últimas estaban vinculadas a la lógica del mercado, al desarrollo del capitalismo y a la construcción de una nueva forma de estado social, alejado del liberalismo clásico. Fue en parte por esa contradicción entre necesidades locales y exigencias nacionales, entre el respeto a las «tradiciones positivas» de los pueblos indígenas y las exigencias de la industrialización, entre apoyos y resistencias, que varios intelectuales y políticos revolucionarios modificaron de manera paulatina su forma de percibir el «problema indígena» hasta convertirlo en el «problema rural».

\section{Nota sobre el autor}

Marco A. Calderón Mólgora es Doctor en Ciencias Antropológicas y Sociólogo Político de Licenciatura y Maestría. Durante los últimos quince años ha trabajo diversas cuestiones de historia sociocultural de la educación rural, la antropología y la formación del estado de la posrevolución en México. Haciendo énfasis en distintos «laboratorios culturales» financiados por la Secretaría de Educación Pública, su libro más reciente, en proceso de publicación, se titula Educación rural, «experimentos sociales" y Estado en México, 1910-1933, un trabajo que analiza el cambio cultural asociado a la formación del Estado de la posrevolución. Ejes transversales de diversas publicaciones son cuestiones de ciudadanía, el complejo vínculo entre México y Estados Unidos en materia de educación indígena y rural, así como el papel de la mujer y la familia campesina en la formación de la nación moderna en la primera mitad del siglo xx.

\section{REFERENCIAS}

Aguirre Beltrán, Gonzalo. Teoría y práctica de la educación indígena. México: SEP70, 1973.

ARnAUT, Alberto. Historia de una profesión. Los maestros de educación primaria en México, 1887-1994. México: CIDE, 1996.

- La federalización educativa en México: Historia del debate sobre la centralización y la descentralización educativa (1889-1994). México: El Colegio de México/CIDE, 1998.

Buchenau, Jurgen. Plutarco Elias Calles and the Mexican Revolution. USA: Rowman and Littelfield Publishers, 2007. 
Caloca, Laura. «Exposición de motivos de las bases del Congreso de Misioneros que se celebrará en la capital de la República». Ethnos, Revista dedicada al estudio y mejora de la población indígena de México, 2. época, I (1), (19221923): 63-72.

CooK, Katherine. La casa del pueblo, un relato acerca de las escuelas nuevas de acción en México. México: SEP, 1932.

CORRIGAN, Philip y Derek SAYER. «El gran Arco, La formación del Estado Inglés como revolución cultural». In Antropología del Estado, Dominación y prácticas contestatarias en América Latina, edited by María y Pamela Calla Lagos, 39-74. Bolivia: PNUD, 2007.

FELl, Claude. «La creación del Departamento de Cultura Indígena a raíz de la Revolución Mexicana». In Educación rural e indígena en Iberoamérica, edited by Pilar Gonzalbo, 109-122. México: El Colegio de México, 1999.

GonzÁlez, Ángeles. Manuel Gamio, una lucha sin final. México, UNAM, 1987.

GONZÁLEZ Y GONZÁLEZ, Luis. «El subsuelo indígena». In Historia moderna de México, La República Restaurada, La vida Social, edited by Daniel Cosío Villegas, Tomo III. México-Buenos Aires: Editorial Hermes, 1974.

Huges, Lloyd. The Mexican Cultural Mission Programme. Paris: UNESCO, 1950.

Loyo, Engracia. La casa del pueblo y el maestro rural. México: Ediciones El Caballito/SEP, 1984.

- Gobiernos revolucionarios y educación popular en México, 1911-1928. México: El Colegio de México: México, 1999.

PANI, Francisco. La instrucción rudimentaria en la República. México: Secretaría de Instrucción Pública, 1912.

RAmírez, Elisa. La educación indígena en México. México: UNAM, 2006.

RozAt, Guy. Los orígenes de la Nación. Pasado indígena e historia nacional. México: Universidad Iberoamericana, 2001.

Secretaría de Educación Pública. Las Misiones Culturales 1932-1933. México: Secretaría de Educación Pública, 1933.

STABB, Martin. «Indigenism and Racism in Mexican Thought: 1857-1911». Journal of Inter-American Studies, 1 (4), (1959): 405-423.

STANLEY, Joseph. "La casa del pueblo: México Experiments in Rural Education» PhD diss., Stanford University, 1948.

URÍAS, Beatriz. Indígena y Criminal: Interpretaciones del derecho y la antropología en México. México: Universidad Iberoamericana, 2000.

Vasconcelos, José. El Movimiento Educativo en México. México: Talleres Gráficos de la Nación, 1922.

- Memorias II. El desastre. México, FCE, 1982.

Vaughan, Mary Kay. State, Education and Social Class in Mexico, 1880-1928. Chicago: Universidad de Illinois, 1982. 